\title{
Development of vertical and horizontal disk transducers for wave velocity measurements in a large rectangular specimen
}

\author{
Troyee Tanu Dutta ${ }^{1, *}$, Masahide Otsubo ${ }^{1}$, Reiko Kuwano ${ }^{1}$, and Takeshi Sato ${ }^{1}$ \\ ${ }^{1}$ Institute of Industrial Science, The University of Tokyo, Japan
}

\begin{abstract}
For the accurate design of structures subjected to both static and dynamic loadings, elastic wave velocity and small strain stiffness are essential parameters. Numerous techniques have been developed to estimate wave velocities of geomaterials. Bender elements which are widely adopted for wave velocity measurements are invasive in nature and are not suitable for coarse-grained materials. In the present study, new design configuration of disk transducer has been introduced to measure both vertical and horizontal wave velocities for coarse granular soils considering multidirectional oscillation of propagating waves. An innovative arrangement of both compression and shear type elements has been installed in a large-sized triaxial apparatus having rectangular specimens of size $236 \times 236 \times 500 \mathrm{~mm}$ to assess the wave velocities. The materials described are Toyoura sand $\left(D_{50}=0.24 \mathrm{~mm}\right)$ and Oiso gravel $\left(D_{50}=11.8 \mathrm{~mm}\right)$. This arrangement enables measurements of nine types of wave velocities, and thus the stiffness anisotropy to be quantified. For Oiso gravel, horizontal wave velocities are greater than vertical wave velocities for both shear and compression waves. For Toyoura sand, shear wave velocities are higher in horizontal direction of propagation, whereas similar compression wave velocities are observed from both horizontal and vertical directions.
\end{abstract}

\section{Introduction}

The precise analysis and design of geotechnical structures subjected to both static and dynamic loadings require accurate estimation of small strain stiffness, often quantified using elastic wave velocities. A sound understanding of the small strain stiffness parameters is vital for the prediction of ground movements that may influence nearby structures and buried infrastructures [1]. Due to the simplicity of use, piezoelectric transducers have gained immense popularity for the estimation of small strain stiffness by performing wave measurements. In this regard, bender and extender elements are extensively used to obtain the shear wave $\left(V_{s}\right)$ and compression wave velocities $\left(V_{p}\right)$, respectively [2-5]. However, there are few limitations involved in the bender element technique; due to their invasive nature, bender elements are not suitable for wave velocity measurements of coarse-grained particles (coarse sands and gravels), undisturbed and cemented specimens. Therefore, previous researchers started adopting planar shaped piezoelectric transducers, also referred to as shear plate transducers [6-8] and disk transducers (DT) [9-10], to measure elastic wave velocities. Nevertheless, there has been a limited research conducted on the development and use of planar piezo-ceramic transducers to estimate wave velocities of coarse granular materials (gravels) [11]. Moreover, there is a research gap present on the development and use of planar piezo-ceramic transducers to estimate horizontal wave velocities in soils.

In the present study, the development of a novel test setup which enables the estimation of nine types of wave velocities to discuss the stiffness anisotropy of geomaterials is described. Due to the large specimen size $(236 \times 236 \times 500 \mathrm{~mm})$, this device is capable of measuring wave velocities $\left(V_{s}\right.$ and $\left.V_{p}\right)$ of soils having a wide range of mean particle sizes $\left(D_{50}\right)$ (from fine sands of $0.2 \mathrm{~mm}$ to gravels of $12 \mathrm{~mm}$ ).

\section{Materials Used}

To demonstrate the suitability of the current setup to test a wide range of $D_{50}$, the materials described in the present paper are Toyoura sand and Oiso gravel. Toyoura sand is a uniformly graded fine sand having $D_{50}$ of $0.24 \mathrm{~mm}$ (Figure 1). Oiso gravel is a uniformly graded, moderately rounder, elongated gravel having $D_{50}$ of $11.8 \mathrm{~mm}$ (Figure $1)$. The specific gravity $\left(G_{s}\right)$ and coefficient of uniformity $\left(U_{c}\right)$ of Toyoura sand are 2.642 and 1.36 , respectively. The minimum void ratio $\left(e_{\min }\right)$ and maximum void ratio $\left(e_{\max }\right)$ of Toyoura sand are 0.569 and 0.936 , respectively. The $G_{s}$ and $U_{c}$ of Oiso gravel are 2.57 and 1.22, respectively. The Oiso gravel has $e_{\min }$ and $e_{\max }$ of 0.480 and 0.624 , respectively.

\footnotetext{
* Corresponding author: t-dutta@iiis.u-tokyo.ac.jp
} 


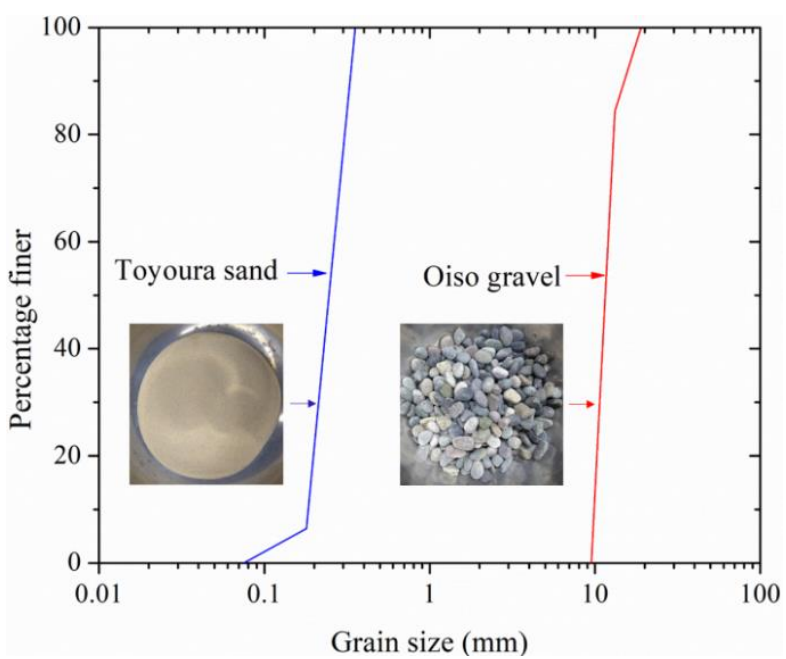

Fig. 1. Grain size distributions

\section{Disk transducers}

\subsection{Vertical disk transducers}

The compression (P-) and shear (S-) elements are industrially manufactured (by Fuji Ceramics Corporation), planar, disk type piezoelectric transducers of size $20 \mathrm{~mm}$ in diameter and $2 \mathrm{~mm}$ in thickness. Figure 2a schematically illustrates the components of the vertical disk transducer. An $80 \mathrm{~mm}$ diameter stainless steel disk acts as a single unit and for each transmitter and receiver assembly, eight numbers of S-plates and four numbers of P-plates were used. Considering the sample length (500 $\mathrm{mm}$ ), for each layer of S- and P-plates, a circular arrangement of four disks were used to amplify the signal (Figure 2a).

A pair of four S-plates with the direction of oscillation in mutually perpendicular orientation were glued by epoxy resin on either side of an acrylic disk of thickness $1 \mathrm{~mm}$ to form a SS-type assembly (Figure 2b). The P-plates were carefully glued to an acrylic plate and was located farther from the soil specimen (Figure 2c). The merged SS-plates were then glued to P-plates and were separated by means of acrylic disk of thickness $1 \mathrm{~mm}$ to make an SSP-type arrangement (Figure 2d). In this step, utmost care should be taken to ensure that for each layer of SSplates, the directions of oscillation of all four plates are kept same. A circular stainless steel disk of diameter 86 $\mathrm{mm}$ was screwed on the P-side of the SSP-arrangement. S side of the SSP-assembly was glued to a $1 \mathrm{~mm}$ thick acrylic plate which was later attached to another $80 \mathrm{~mm}$ diameter stainless steel disk.

The developed transmitter and receiver elements are shown in Figure 3. Before adopting the transmitter and receiver elements to perform wave measurements, calibration exercise was carried out to determine the time lag in the assembly by attaching both faces of the transmitter and receiver elements (Figure 4a).

The excitation wave signals in the present study were generated using a digital function generator and were amplified $(\times 20)$ by a bipolar amplifier. Sinusoidal waveform of input frequency $\left(f_{\text {in }}\right) 10 \mathrm{kHz}$ was applied, and the input and output signals were recorded using an oscilloscope. The time domain responses during direct contact of the disk transducers indicate negligible time lag, although P-plates located on the farther side demonstrate slightly lower amplitudes as compared to Splates (Figure $4 \mathrm{~b}$ ). A parallel connection is given to the transmitter to provide an equal input voltage to all the transmitting elements, whereas series connection was used for the receiver elements to secure maximum output voltage. The transmitter is screwed to a rectangular stainless steel plate (Figure 5a) which is attached to the top cap, whereas the receiver is screwed directly to the bottom pedestal of the triaxial apparatus (Figure 5b).

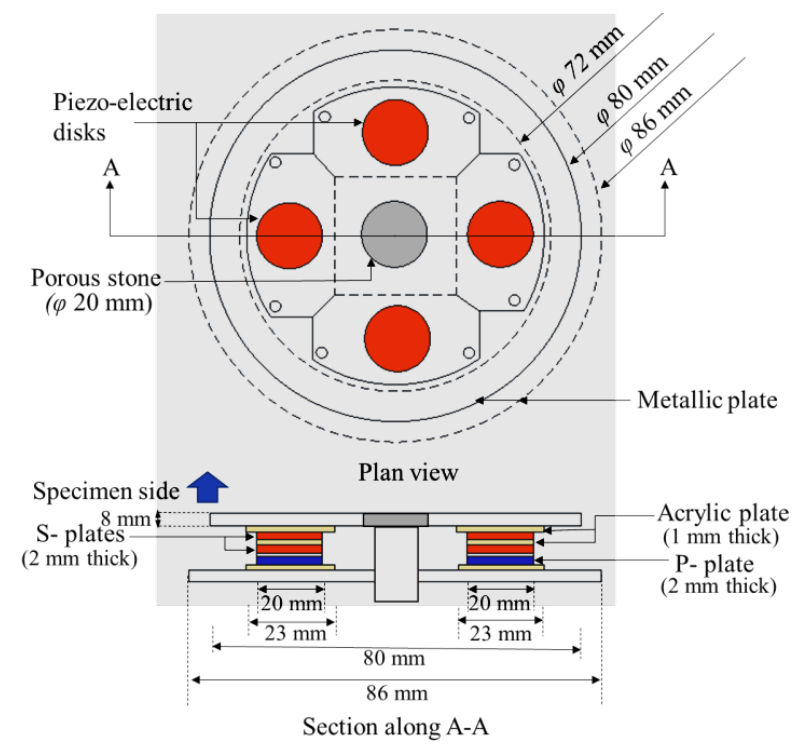

(a)

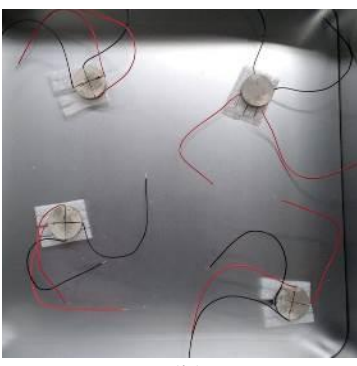

(b)

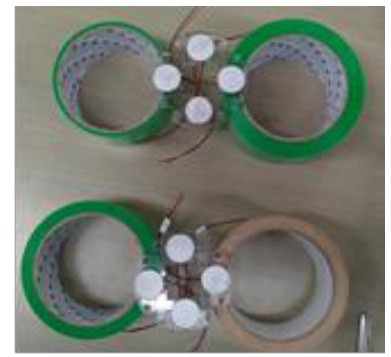

(c)

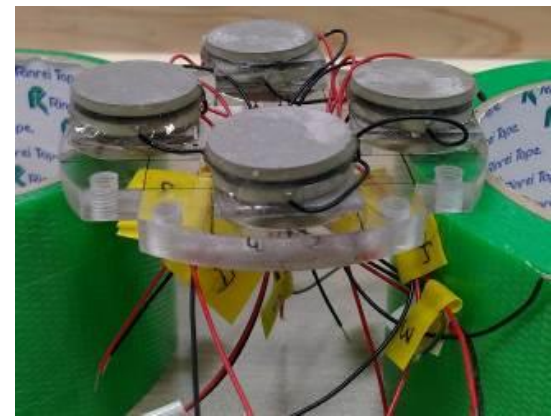

(d)

Fig. 2. (a) Schematic design of vertical disc transducer (b) Merged S-plates (SS-type arrangement) (c) P-plate glued to acrylic disk (d) SSP- arrangement 


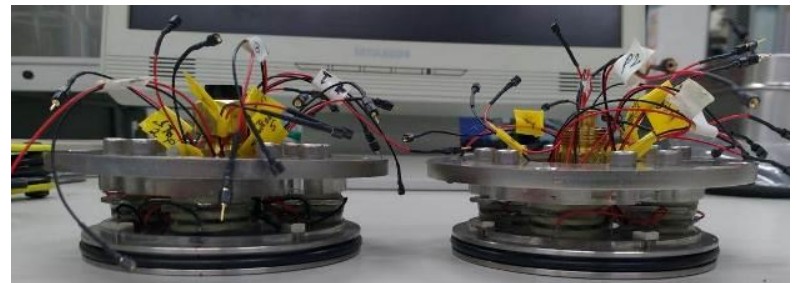

Fig. 3 Transmitter and receiver vertical disc transducers

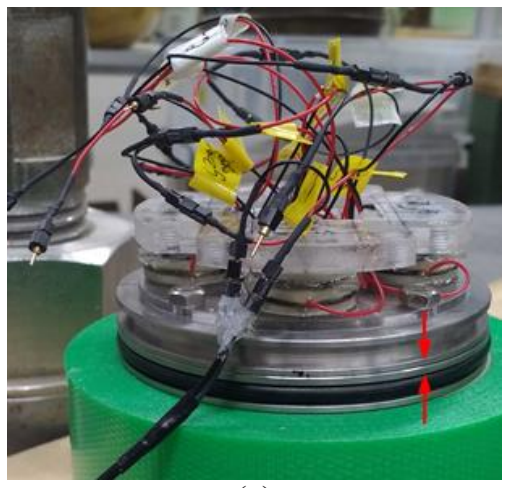

(a)

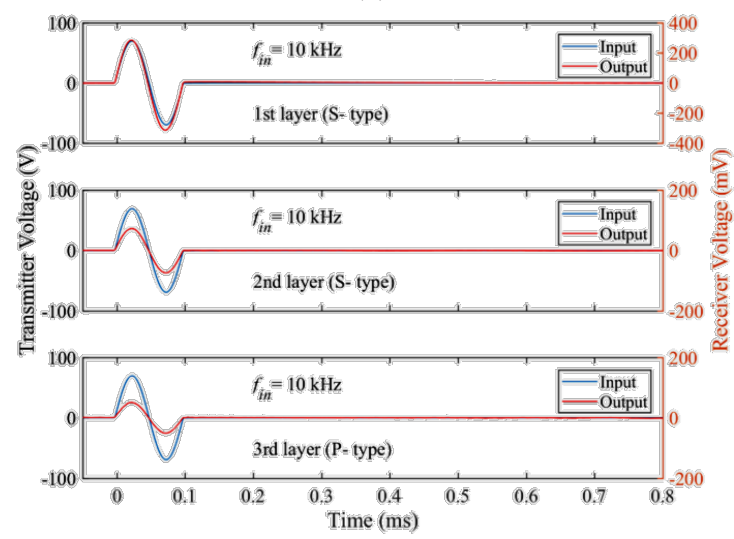

(b)

Fig. 4. (a) Direct contact for calibration (b) Time domain responses during direct contact

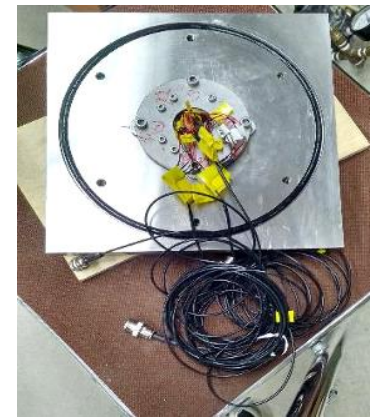

(a)

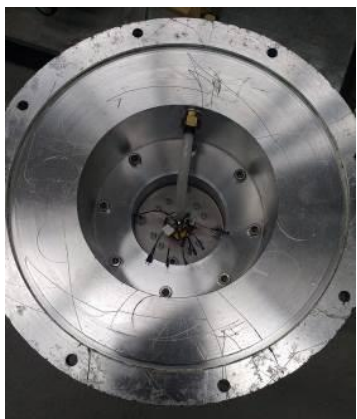

(b)
Fig. 5. (a) Transmitter element attached to a stainless steel plate of top cap (b) Receiver element screwed to bottom pedestal

\subsection{Test setup \& horizontal disk transducers}

In the membrane (of thickness $2 \mathrm{~mm}$ ), twelve numbers of $20 \mathrm{~mm}$ diameter holes were made and $50 \times 50 \mathrm{~mm}$ aluminum plates of thickness $1 \mathrm{~mm}$ were glued on the inside of the membrane by using silicon. Sufficient care must be taken to prevent leakage through the holes. The membrane was attached to the bottom pedestal by rubber straps, and cubical split mold was used to prepare specimens of size approximately $236 \times 236 \times 500 \mathrm{~mm}$ (Figure 6a). The specimens were pluviated inside the mold in ten layers, and dry tamping method was used to compact each layer.

After preparing the specimen, on each face, one P- and two $\mathrm{S}$ - plates were fixed by a rapid hardening glue to the aluminum plates and were separated by $1 \mathrm{~mm}$ thick acrylic disk (Figures $6 \mathrm{~b}$ and $6 \mathrm{c}$ ). This novel arrangement of vertical and horizontal disk transducers (DTs) facilitates the measurement of nine types of wave velocities to describe the stiffness anisotropy (Figure 7). The notation of wave velocity of the form $V_{s(x y)}$ indicates a shear wave propagating in the $x$-direction and oscillating in the $y$-direction.
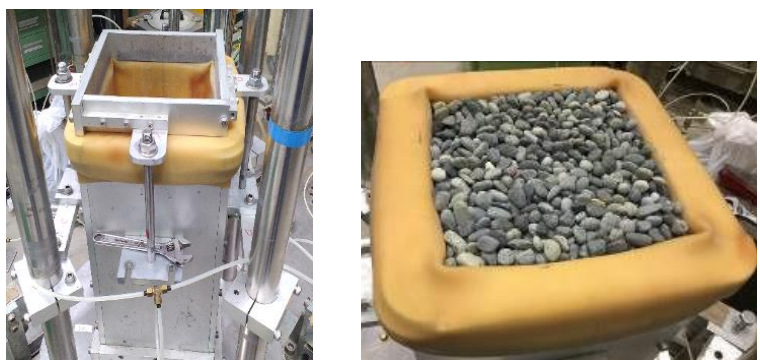

(a)
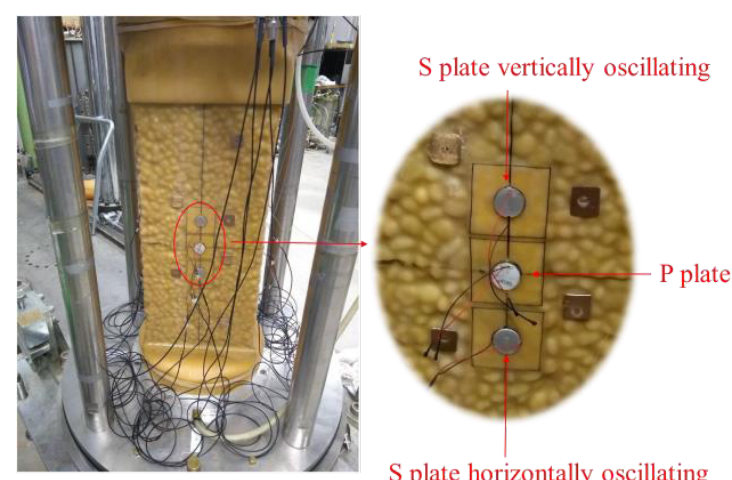

S plate horizontally oscillating

(b)

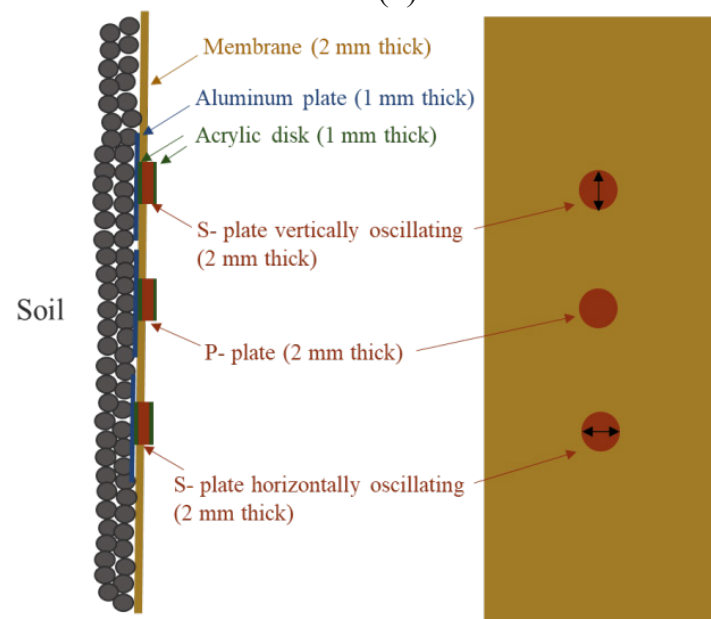

(c)

Fig. 6. (a) Rectangular split mould (b) Oiso gravel specimen with horizontal DTs (c) Schematic of horizontal DTs 

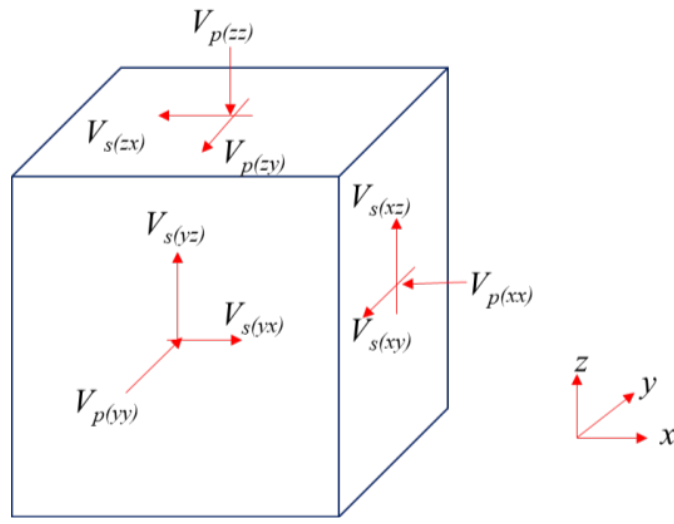

Fig. 7. Soil element depicting nine types of wave velocities

A Toyoura sand specimen was prepared at a void ratio and relative density of 0.780 and $43 \%$, respectively. An Oiso gravel specimen was prepared at a void ratio and relative density of 0.499 and $87 \%$, respectively. Peak-to-peak method was used to obtain $V_{s}$ as rise signals are affected by near-field effect. The $V_{s}$ evaluated from the peak-to-peak method and rise-torise method were in good agreement (within 2\%) when input frequency matches with one of the dominant frequencies, but elaborate discussions have not been reported here. For $V_{p}$ estimates, rise-to-rise method as described in Suwal and Kuwano [9] was used

\section{Results and discussion}

\subsection{Time domain and frequency response}

The time domain responses of $\mathrm{P}$ - and $\mathrm{S}$-waves propagating in $x, y$ and $z$ directions of Oiso gravel and Toyoura sand are depicted in Figures 8 and 9, respectively. Rise points in P-waves and first peak of $\mathrm{S}$-waves are indicated by black arrows. The time domain plots are shown for $f_{\text {in }}$ corresponding to one of the dominant frequencies of the soils.

Due to smaller $D_{50}$ of Toyoura sand as compared to Oiso gravel, higher frequency components can be spotted in the time domain responses of $\mathrm{P}$ - and $\mathrm{S}$ waves [12]. Moreover, the amplitudes of output time domain signals are considerably higher in case of Toyoura sand as compared to Oiso gravel.

The transfer function of a system offers a direct relation between transmitted and received signals and is unique and independent of input excitation [13]. The variation of gain factor $\left(F F T_{\text {output }} / F F T_{\text {input }}\right)$ with frequency (Figure 10) depicts a larger gain for Toyoura sand in comparison to Oiso gravel, which explains the observation of high amplitude output responses in case of Toyoura sand than Oiso gravel. It can be also stated from Figure 10 that the range of frequency propagation is higher for Toyoura sand as compared to Oiso gravel.

\subsection{Anisotropy of wave velocities}

The various multidirectional $V_{s}$ for $30 \mathrm{kPa}$ and $50 \mathrm{kPa}$ isotropic confinement of Oiso gravel and Toyoura sand are shown in Figure 11a and 11b, respectively. The blue and red lines indicate waves propagating in vertical and horizontal directions, respectively.

For Oiso gravel (Figure 11a), the order of shear wave velocities is $V_{s(y z)}>V_{s(x y)} \approx V_{s(y x)}>V_{s(x z)}>V_{s(z y)}>V_{s(z x)}$. The hypothesis of cross anisotropy which is not demonstrated by Oiso gravel may be attributed to the large particle size. For Oiso gravel, larger shear wave velocity has been observed from both vertical and horizontal wave measurements in $y$ direction as compared to $x$ direction.

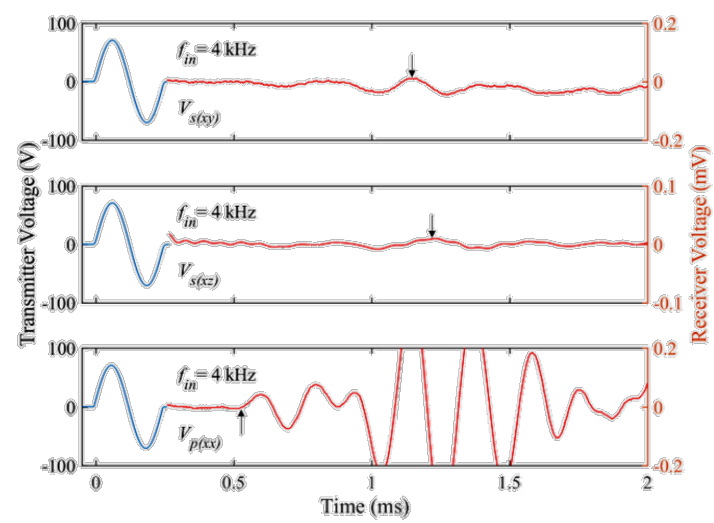

(a)

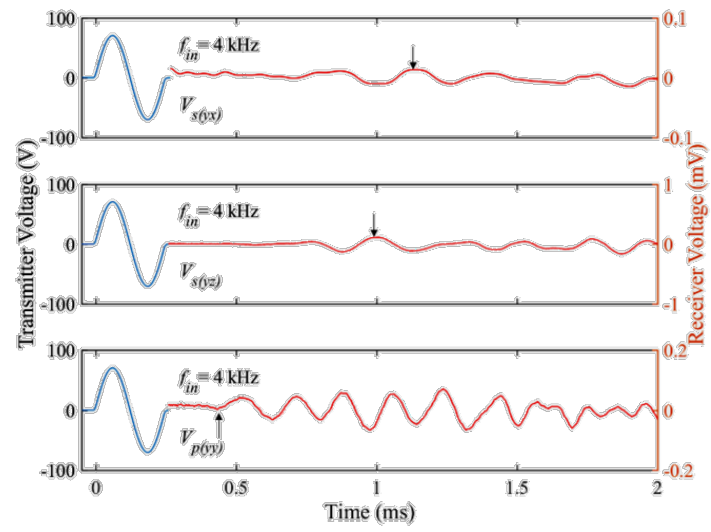

(b)

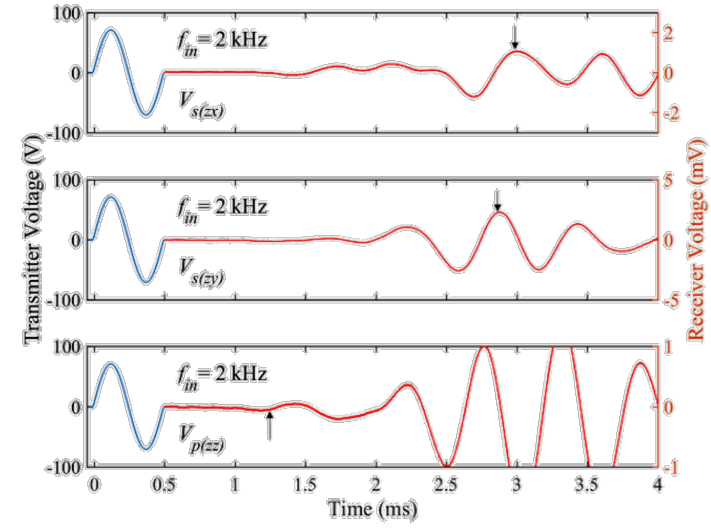

(c)

Fig. 8. Time-domain response of Oiso gravel ( $p^{\prime}=50 \mathrm{kPa}$ $\left.\& e_{o}=0.499\right)$ propagating in (a) $x\left(l_{x}=237.8 \mathrm{~mm}\right)$ (b) $y$ 
$\left(l_{y}=236.5 \mathrm{~mm}\right)(\mathrm{c}) z\left(l_{z}=499.9 \mathrm{~mm}\right)$ directions (First peak and rise point indicated by black arrow)

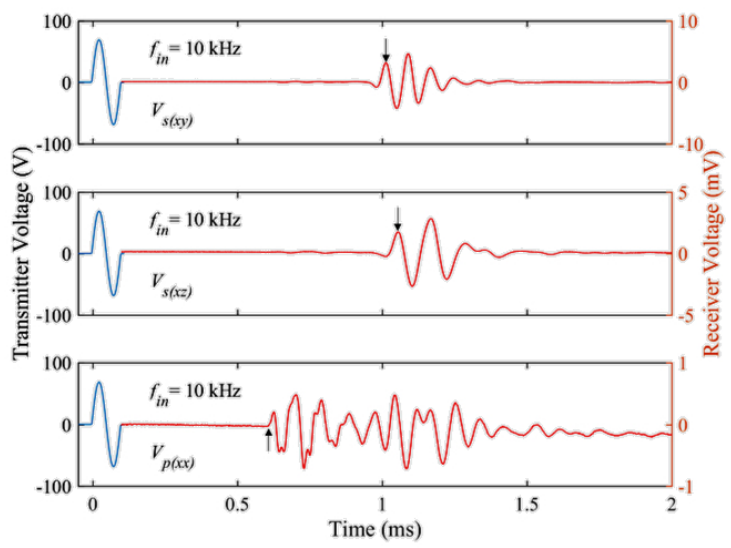

(a)

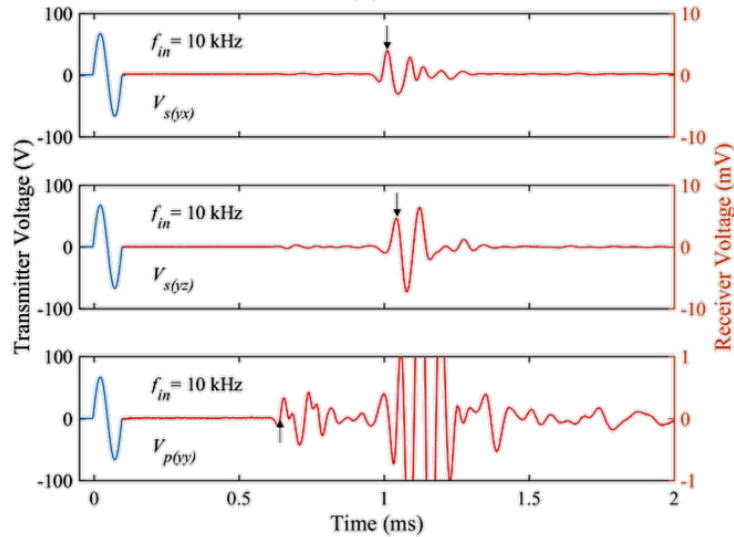

(b)

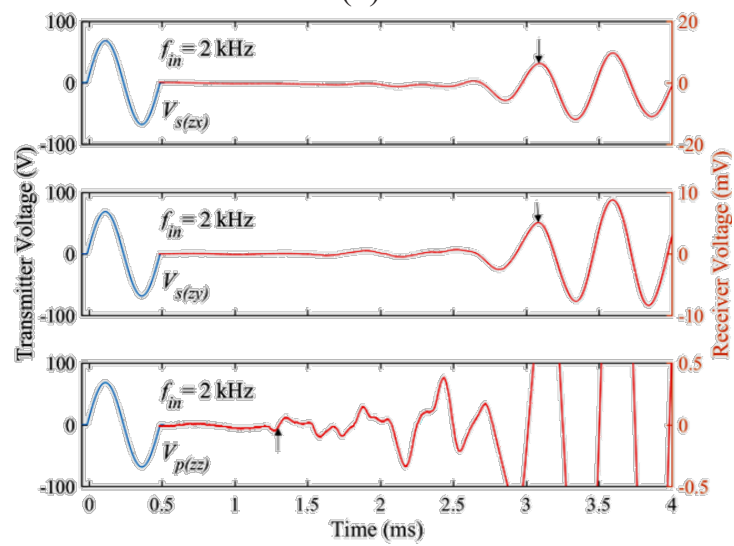

(c)

Fig. 9. Time-domain response of Toyoura sand ( $p^{\prime}=50 \mathrm{kPa}$ $\left.\& e_{o}=0.780\right)$ propagating in (a) $x\left(l_{x}=235.2 \mathrm{~mm}\right)$ (b) $y\left(l_{y}\right.$ $=236.1 \mathrm{~mm})(\mathrm{c}) z\left(l_{z}=499.9 \mathrm{~mm}\right)$ directions (First peak and rise point indicated by black arrow)

For Toyoura sand (Figure $11 \mathrm{~b}$ ), the order of shear wave velocities is $V_{s(x y)} \approx V_{s(y x)}>V_{s(y z)} \approx V_{s(x z)}>V_{s(z y)} \approx$ $V_{s(z x)}$. Consequently, the approximation of a horizontally isotropic and cross anisotropic behavior [14] of Toyoura sand subjected to isotropic stresses is found to be valid.

For both Oiso gravel and Toyoura sand, $V_{s}$ for waves propagating in horizontal directions are found to be higher than waves propagating in vertical direction (Figure 11). Previous experimental research performed in triaxial apparatus equipped with bender elements also support this observation [15]. It was reported that $V_{S}$ is greater when propagation direction is parallel to the longer axes of the specimen as compared to $V_{s}$ of specimen where oscillation direction is parallel to the longer axes [14].

For Oiso gravel (Figure 12a), the order of compression wave velocities is $V_{p(y y)}>V_{p(x x)}>V_{p(z z)}$. However, for Toyoura sand (Figure 12b), the compression wave velocities vary in a narrow range and the inherent anisotropy of $V_{p}$ is observed to be small.

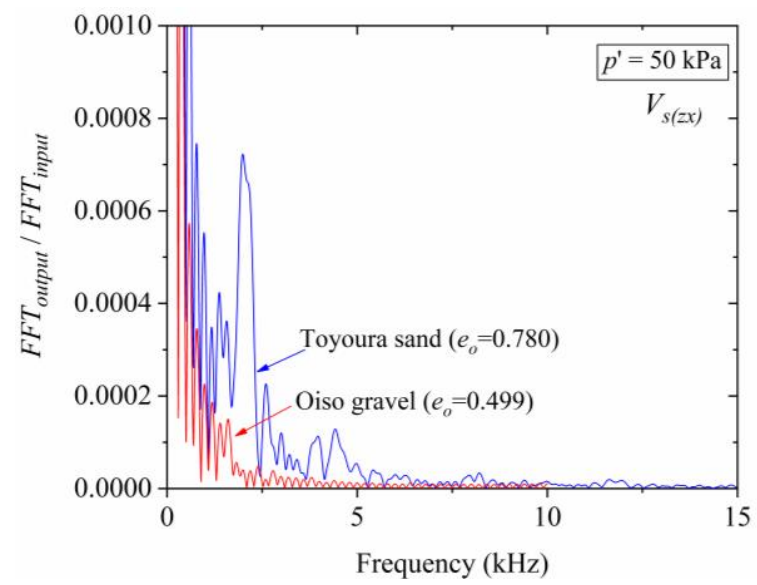

Fig. 10. Gain factor for Toyoura sand and Oiso gravel (for $\left.V_{s(z x)}\right)$

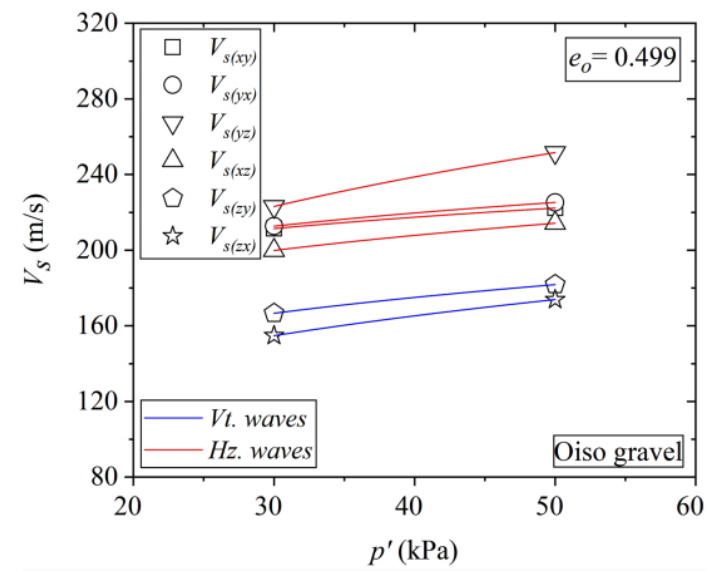

(a)

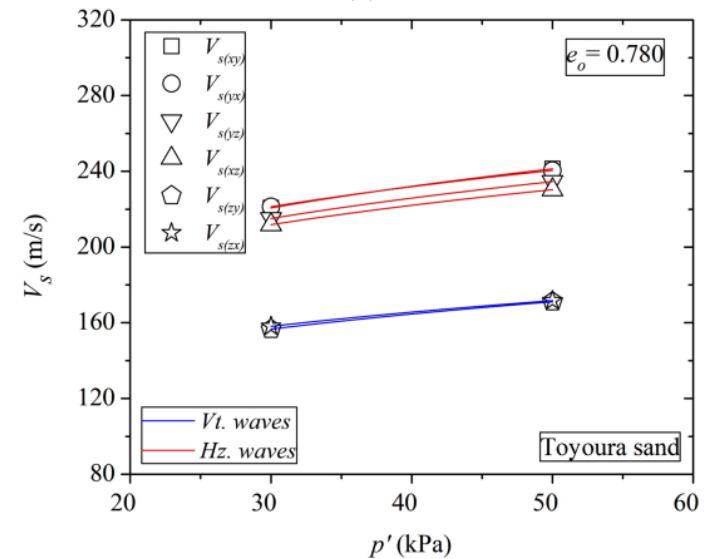

(b)

Fig. 11. $V_{s}-p^{\prime}$ for (a) Oiso gravel $\left(e_{o}=0.499\right)$ (b) Toyoura sand $\left(e_{o}=0.780\right)(V t$. - Vertical \& Hz. - Horizontal waves $)$ 


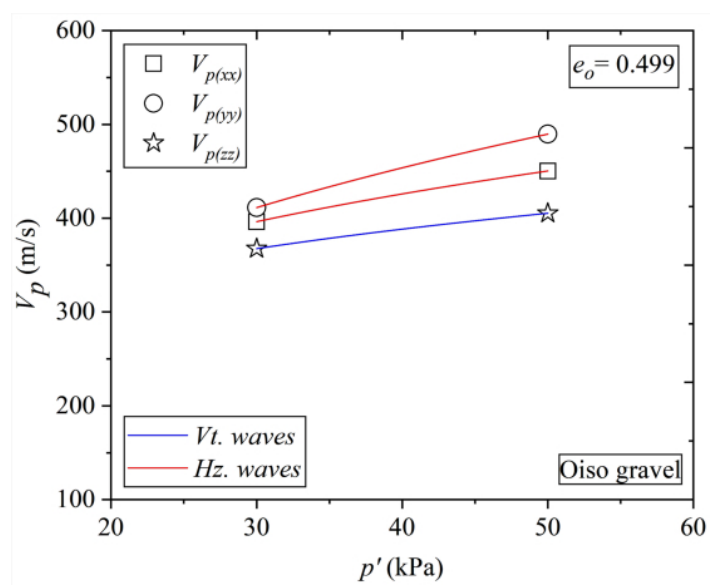

(a)

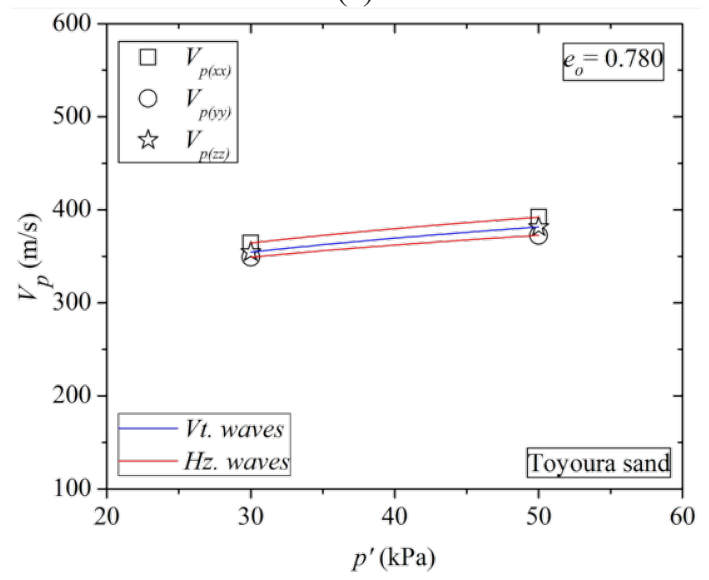

(b)

Fig. 12. $V_{p}-p^{\prime}$ for (a) Oiso gravel $\left(e_{o}=0.499\right)$ (b) Toyoura sand $\left(e_{o}=0.780\right)(V t .-$ Vertical \& Hz. Horizontal waves)

\section{Conclusions}

In the present study, the development of an innovative arrangement of planar piezoelectric transducers is described to obtain nine types of wave velocities required to describe the stiffness anisotropy of geomaterials. The current assembly of disk transducers is suitable for the measurement of wave velocities for a wide range of particle sizes. To describe the effectiveness of this technique, Toyoura sand $\left(D_{50}=0.24 \mathrm{~mm}\right)$ and Oiso gravel $\left(D_{50}=11.8\right.$ $\mathrm{mm}$ ) were used and following conclusions can be drawn.

1) For Oiso gravel, horizontal wave velocities are observed to be considerably greater than vertical wave velocities.

2) For Toyoura sand, the horizontal shear wave velocities are greater than vertical shear wave velocities.

3) For Toyoura sand, horizontal and vertical compression wave velocities are found to be comparable.

4) Better output signals have been observed for the fine sand as compared to gravel due to the presence of larger gain factor from the frequency domain response.
Moreover, for Toyoura sand subjected to isotropic stress state, the approximation of a horizontally isotropic and cross anisotropic behavior described in the previous research is found to be valid.

\section{References}

1. C.R.I. Clayton, Géotechnique 61, 1, 5-37 (2011)

2. D.J. Shirley, L. D. Hampton, J. Acoust. Soc. Am. 63, 2, 607-613 (1978)

3. R. Dyvik, C. Madshus, Proc. ASCE Ann. Conv. Adv. Art Test. Soils Und. Cyc. Con., Detroit, Michigan, 186-196 (1985)

4. G. Viggiani, J. H. Atkinson, Géotechnique 45, 1, 149-154 (1995)

5. R. Kuwano, R.J. Jardine, Géotechnique 52, 10, $727-$ 750 (2002)

6. E. Brignoli, M. Gotti, K. Stokoe, Geotech. Test. J. 19, 4, 384-397 (1996)

7. M.A. Ismail, K.I. Rammah, Géotechnique 55, 5, 403 407 (2005)

8. M. Otsubo, C. O’Sullivan, Soils Found. 58, 3, 602614 (2018)

9. L.P. Suwal, R. Kuwano, Soils Found. 53, 4, 510-524 (2013)

10. A. Pokhrel, R. Kuwano, L.P. Suwal, Proc. Int. Sym. Deformation Characteristics of Geomaterials, Buenos Aires, Argentina, 366-373 (2015)

11. A. Pokhrel, Master's dissertation, The University of Tokyo, Japan (2014)

12. J. Yang, X. Q. Gu, Géotechnique 63, 2, 165-179 (2013)

13. G. Alvarado, M. R. Coop, Géotechnique 62, 1, 1-17 (2011)

14. E. Hoque, F. Tatsuoka, Soils Found. 38, 1, 163-179 (1998)

15. J. C. Santamarina, G. C. Cho, Proc. Skempton Conf: Adv. Geotech. Engg., London, UK, 604-617 (2004) 